\title{
Espacios culturales alternativos: la Roma-Condesa en la Ciudad de México*
}

\author{
Alternative cultural spaces: \\ Roma-Condesa area in Mexico City
}

\author{
ROCÍO GUADARRAMA OLIVERA** \\ MARÍA MORENO CARRANCO***
}

\begin{abstract}
Alternative cultural spaces are characterized as much by the way they gather cultural and creative activities, as by the fluid relationships among sites for habitation, work, and leisure. From these gatherings and relationships, spatial heterogeneous ways of belonging and identity coalesce into the area known as Roma-Condesa in the center of Mexico City. The theoretical possibilities of the concept and the results of a mixed methods model stemming from the testimonials of inhabitants in the area, the spatial localization of activities and creators, and the registry of their creative processes in the urban transition between the earthquakes of 1985 and 2017 are evaluated.
\end{abstract}

Key words: space, culture, spatial identity, urban transformations, everyday life

\section{Resumen}

Los espacios culturales alternativos se caracterizan tanto por la concentración de actividades culturales y creativas como por relaciones fluidas entre lugares de habitación, trabajo y entretenimiento. De ahí surgen formas de pertenencia e identidad territorial heterogéneas, como en la zona Roma-Condesa, en el centro de la Ciudad de México. Se evalúan las posibilidades teóricas del concepto y las resultantes de un modelo metodológico mixto nutrido de la memoria de los habitantes de la zona, la localización espacial de actividades $y$ creadores $y$ el registro de sus procesos creativos en la transición urbana entre los sismos de 1985 y 2017. Palabras clave: espacio, cultura, identidad territorial, transformaciones urbanas, vida cotidiana

\section{Introducción}

Q 1 análisis relacionado con la construcción social de los espacios urbanos nos remite a la obra clásica $L a$ production de l'espace del filósofo y sociólogo Henri Lefebvre, la cual vio la luz en 1974, y que constituyó un parteaguas en el pensamiento social contemporáneo al introducir el análisis del espacio como una dimensión fundamental en el estudio de la vida cotidiana (Lefebvre, 2013). El resultado de este proceso de mediación reflexiva es el concepto de espacio social.

* Artículo recibido el 19/04/19 y aceptado el 12/06/19.

** Universidad Autónoma Metropolitana, Unidad Cuajimalpa, Departamento de Ciencias Sociales. Av. Vasco de Quiroga núm. 4871, col. Contadero, 05370, Ciudad de México <rocio.guadarrama.o@gmail.com>. orciD: http://orcid.org/O000$0001-6614-6772$.

*** Universidad Autónoma Metropolitana, Unidad Cuajimalpa, Departamento de Ciencias Sociales. Av. Vasco de Guiroga núm. 4871, col. Contadero, 05370, Ciudad de México <maria.moreno.carranco@gmail.com>. oRciD: http://orcid. org/0000-0002-5719-7962. 
A partir de la publicación de esta obra son muchos los esfuerzos empeñados en examinar los procesos que intervienen en la construcción del espacio en cuanto soporte de la vida social, en especial desde la geografía humana (Hart, 2002; Massey, 1993, 1994; Soja, 1996). Con base en estos antecedentes, en la presente investigación abordamos dicha problemática desde un ángulo que se propone descubrir los procesos de concentración de actividades culturales y de creación artística en algunos espacios de la Ciudad de México. Por esta vía analítica, nos alejamos de la influyente teoría de la clase creativa, acuñada por el urbanista Richard Florida (2005), que relaciona los altos niveles de desarrollo económico de las regiones metropolitanas de las ciudades del primer mundo con la aglomeración de miembros de las profesiones vinculadas con las nuevas tecnologías, servicios avanzados y procesos creativos en distintos campos del conocimiento. En contrapartida con esta visión del espacio atada a los "exitosos", y como habitantes de una metrópoli extremadamente heterogénea y desigual, como es la Ciudad de México, adoptamos el punto de vista más horizontal y abierto de la antropología urbana que coloca en el centro la dialéctica entre espacio y sujeto. ${ }^{1}$ Esta perspectiva se resume en el acto de habitar, como bien afirma Angela Giglia (2012: 10), que tiene que ver con "la capacidad humana de interpretar, reconocer y significar el espacio".

En el lenguaje más abstracto de la sociología cultural, el acto de habitar hace patente, a los ojos del observador y en el momento hermenéutico del análisis, los modos en que los actores sociales "impregnan de sentimiento y significado sus mundos" (Alexander, 2000: 32 y 129). Nuestra estrategia en esta investigación consiste, precisamente, en considerar este procedimiento hermenéutico, que pone entre paréntesis, por un momento, el contexto social más amplio, estructural, para entresacar los sentimientos de los actores y su capacidad de otorgar significado a sus mundos habitados. Estos mundos son construidos a través de la memoria individual y colectiva, algunas veces añorando el pasado, otras celebrando el presente, develando de esta forma la construcción subjetiva de la ciudad.

Para conocer las particularidades de este tipo de aglomeraciones culturales desde la experiencia de sus habitantes, elegimos como espacio de investigación una zona céntrica de la Ciudad de México, que identificamos como la Roma-Condesa, ${ }^{2}$ la cual constituye un buen ejemplo de las transformaciones culturales urbanas posteriores a los sismos de 1985. Estos fenómenos telúricos tuvieron un ingente impacto en las zonas centrales de la ciudad. Tan sólo en la colonia Roma se colapsaron 63 edificios, mientras que la vecina colonia Condesa tuvo muchísimo menos daños, con seis edificios caídos, aunque eso no impidió que numerosas familias abandonaran la zona. La oferta de inmuebles generada, sobre todo en la Condesa, por la migración a otras áreas de la ciudad percibidas como sísmicamente más seguras, y el despoblamiento de la Roma, constituyeron el punto de inflexión de la vocación de la zona analizada en este escrito.

Pasadas más de tres décadas, la Roma-Condesa renacería como un espacio que se distingue por la presencia de una importante cantidad de personas y negocios que se especializan en actividades vinculadas con la creación, el arte y la cultura. Éstos conviven con los antiguos habitantes en un contexto caracterizado por los diferentes usos de suelo, en el cual se mezclan construcciones de gran valor patrimonial con edificios habitacionales y oficinas de arquitectura contemporánea.

Para explicar esta concentración abigarrada de personas, construcciones, actividades y gustos, buscamos comprender las formas de relación y movilidad puestas en juego por la gente entre sus lugares de residencia, trabajo y entretenimiento. Al igual que Savage, Bagnall y Longhurst (2005: 132), pensamos que estas relaciones son fundamentales en el mundo actual para explicar la formación de clase de las personas y grupos sociales. En particular, de quienes eligen pertenecer a un espacio habitacional específico, congruente con un estilo de vida con aspiraciones cosmopolitas y globales. Intentamos también resaltar los sentimientos contradictorios de los sujetos que habitan estas colonias (los de los residentes más antiguos y los de los recién llegados) y sus vínculos emocionales con estos espacios que, afirman, les pertenecen, ya sea por las raíces históricas de los primeros, o porque responden a sus gustos y a su capital cultural, de acuerdo con los segundos. Este ensamblaje urbano, que pretende ser "algo distinto", según los sentimientos de sus habitantes, es lo que en adelante llamaremos espacio cultural alternativo. Añadimos este último

1 Tal como se muestra en las investigaciones sobre los espacios urbanos latinoamericanos de García Canclini (2004), Giglia (2012) y Duhau y Giglia (2016).

2 Cuando hablamos de la zona Roma-Condesa nos referimos al espacio conformado por cinco colonias o barrios: Condesa, Hipódromo, Hipódromo Condesa, Roma Norte y Roma Sur, situadas en el extremo suroriental de la antigua delegación Cuauhtémoc, hoy denominada alcaldía. 
adjetivo para enfatizar la idea de que el espacio responde a los gustos y emociones de la gente que lo habita, y no sólo se ajusta a los modelos habituales u oficiales de convivencia comúnmente aceptados. En resumen, buscamos desmantelar las narrativas que generalizan sobre los llamados SoHos urbanos-que los describen en términos de gentrificación, homogeneización y pérdida de identidad- para acercarnos más a la experiencia de los sujetos que habitan esta zona.

\section{Antecedentes}

Un somero repaso en torno a este campo de estudio, de manera señalada en el contexto anglosajón, nos remite de inmediato al concepto de clase creativa de Richard Florida (2002, 2003, 2005, 2009). Desde una perspectiva económica, este autor analiza el papel de los creadores -artistas, comerciantes de arte y profesionistas altamente calificados- en los procesos de renovación urbana. De acuerdo con Florida, la "vuelta a la ciudad" de este grupo heterogéneo detonó un tipo de oferta de consumo muy especializado, sostenido en la innovación constante. En su opinión, a ellos se debe el crecimiento económico de algunas ciudades, su florecimiento y diversidad cultural. A pesar de la amplia aceptación de esta teoría entre empresarios y políticos, son muchas las críticas surgidas en el medio académico sobre lo que parece un intento fallido de vincular crecimiento urbano y actividades creativas y culturales (Krätke, 2012; Bayardo, 2013).

En particular cabe destacar la postura de Zukin (2008 y 2010), quien critica el tono celebratorio que permea los estudios de Florida y sus seguidores sobre las ciudades creativas y sus barrios (como el SoHo neoyorkino), que ocultan los fenómenos que hoy día caracterizan a las grandes ciudades (aburguesamiento, gentrificación y falta de autenticidad).

En las metanarrativas de ciudades y redes globales, descritas por autores como Hall (1997), Friedmann (1995), Sassen (1991, 1994), Davis (2004)y Taylor (1997, 2004), el concepto de competitividad urbana se relaciona con los procesos de planificación en el contexto neoliberal (Montgomery, 2003: 293), y con ciertos patrones de atracción de talento e inversión, revitalización económica y regeneración.

Por su parte, y desde la lógica de la economía cultural, algunos investigadores privilegian el análisis de la dimensión simbólica e inmaterial de los procesos de creación de valor y su anclaje territorial (Vivant y Tremblay, 2010: 8). Desde esta última perspectiva, hay quienes estudian la concentración de los establecimientos y el empleo cultural en las regiones y localidades, o en lugares especiales dentro de las ciudades, denominados distritos o clústeres. Este dinamismo urbano se clasifica en ocasiones bajo el rubro de economía creativa localizada (Herrera-Medina, BonillaEstévez y Molina-Prieto, 2013: 14). Sin embargo, si se miran de cerca, los casos concretos revelan diferencias contrastantes en su dinámica económica y sus significados, derivadas todas ellas de las tensiones cotidianas entre los habitantes, sus singularidades culturales y sus trasfondos históricos distintos.

La idea de distrito cultural alude a la concentración de actividades y lugares artísticos, pero además a los recursos del territorio, como el patrimonio cultural y arquitectónico ya existente, que agregan un valor estético a dichas actividades y promueven el desarrollo económico del distrito. Al respecto, Sacco y Ferilli (2006), cit. por Tremblay, Klein y Fontan (2009: 179), proponen un modelo "sintético" de aglomeración cultural: el distrito cultural transformado (évolué), basado en la integración horizontal de factores culturales y productivos. En su forma aplicada, estos últimos términos aparecen también en documentos de investigación y de análisis estratégico que clasifican las ocupaciones creativas y miden su peso en las economías nacionales (Vivant y Tremblay, 2010; United Nations Conference on Trade and Development, 2010; García Canclini y Piedras Feria, 2008).

A diferencia de este inventario sucinto de términos, que aluden desde una perspectiva básicamente económica a la creatividad y a la transformación productiva y cultural urbana de los distritos o clústeres, ${ }^{3}$ en esta investigación buscamos estudiar las relaciones de sentido y la interculturalidad que se derivan de los nuevos modos de apego de los habitantes de los llamados espacios culturales alternativos. ${ }^{4}$

Desde este enfoque se explican los cambios en las formas de habitar producidos en la Roma-Condesa luego de los sismos de 1985, y su impacto posterior en las ocupaciones y maneras de consumo y entretenimiento que se desarrollarían desde principios del siglo XXI.

Vistos así, estos espacios están lejos de reducirse a la "ventaja económica" que les otorga la proximidad de

3 Que ponen el acento en economías de escala y en los efectos de la aglomeración en el espacio urbano.

4 A esto mismo se refieren Savage, Bagnall y Longhurst (2005: 207) cuando hablan del carácter sustantivo del espacio residencial, en el cual las personas definen su posición social (al tiempo que tienen acceso a otros campos como los relativos a la educación, el empleo y a una extensa oferta cultural vinculada al consumo). 
sus creadores. Se parecen más bien a los lugares de inspiración individual y colectiva de los cuales habla Drake (2003: 515). En un sentido amplio, son espacios en los cuales las experiencias relacionadas con la memoria viva de sus moradores, su vida íntima, sus rutinas domésticas y de trabajo, el gusto y el entretenimiento se traslapan, ocurren casi simultáneamente, ya sea que hablemos de lo que sucede en las plazas públicas, bares, cafés y restaurantes, los despachos y tiendas de diseño y moda y los hogares, que son a su vez lugares de trabajo. Se trata, pues, de sitios donde se enfrentan estos significados diversos que los individuos otorgan a su experiencia cotidiana, de ahí también que se constituyan como espacios de disputa (Duhau y Giglia, 2016: 48). ${ }^{5}$

\section{Metodología}

Para desentrañar las peculiaridades de los espacios culturales alternativos en la Ciudad de México, y en específico de la Roma-Condesa, seguimos una estrategia mixta, que se acerca a la idea del continuum interactivo de Newman y Benz (1998), propuesta que incluye, en distintas etapas, métodos cualitativos y cuantitativos. El énfasis mayor estuvo en los primeros, que consistieron en el estudio histórico contextual de la zona, desde sus orígenes, y la memoria o biografía de su devenir (que tiene en cuenta la experiencia de los sujetos que la habitan o que la han observado a lo largo del tiempo, antes y después de 1985). Se incluyó también el estudio observacional de los lugares, las personas y sus actividades, y su localización a través de recorridos y encuentros casuales, conversaciones y entrevistas geonarrativas, para situar y entender la construcción cotidiana del espacio (Ranade, 2007;
Bell, Phoenix, Lovell y Wheeler, 2015). A la par, se aplicaron entrevistas abiertas y semiestructuradas a tres grupos de creadores (arquitectos, diseñadores y músicos) dirigidas a averiguar las singularidades de sus procesos creativos, los lugares de creación y sus prácticas culturales. ${ }^{6}$ Finalmente, se hizo un registro fotográfico que ilustra los lugares y personas que conforman la zona Roma-Condesa.

Por su parte, los métodos cuantitativos tuvieron un carácter complementario y estuvieron dirigidos a definir operacionalmente a los llamados profesionistas culturales o creadores por la Clasificación Mexicana de Carreras. Con base en datos estadísticos ${ }^{7}$ se demostró la importancia de la Roma-Condesa como área de concentración cultural, atendiendo a los establecimientos, actividades e individuos clasificados por su profesión como culturales y creativos. En el mapa 1 se muestra la concentración de los tres grupos seleccionados de creadores y otras actividades artísticas en la antigua delegación Cuauhtémoc (hoy denominada alcaldía) que corresponde a la zona central de la Ciudad de México (véase mapa 1). Los datos censales y de encuestas nacionales, y su georreferenciación, nos permitieron probar que, en efecto, la Roma-Condesa es una de las áreas de mayor concentración cultural de la Ciudad de México y que este fenómeno va de la mano del crecimiento desbocado de estas actividades y de los creadores entre la población ocupada de profesionistas en la primera década del siglo. Las razones más profundas que los atraen hacia estos lugares nos remiten, otra vez, a los estudios particulares de los tres grupos de creativos destacados. Por límites de espacio, no incluimos aquí esta parte del análisis. ${ }^{8}$

Los siguientes apartados están sostenidos en una síntesis de los testimonios recogidos exclusivamente mediante los procedimientos cualitativos.

5 La zona Roma-Condesa corresponde a las nuevas centralidades que surgieron en la Ciudad de México después de los sismos de 1985, que sobresalen por la coexistencia conflictiva del pasado y el presente. De acuerdo con Duhau y Giglia (2016: 48), estas centralidades constituyen la ciudad del espacio disputado en el cual coexisten "de modo altamente conflictivo y en equilibrio precario, los usos residenciales con los no residenciales; el comercio, los servicios formales y los edificios de oficinas, con la presencia del comercio y las más diversas actividades informales en los espacios públicos".

6 La recopilación de testimonios incluyó en total 86 entrevistas, aplicadas entre 2014 y 2016: 59 semiestructuradas, dirigidas a: a) pequeños comerciantes y empleados de establecimientos tradicionales que conforman la economía local, de barrio (peluquerías, tlapalerías, tiendas de abarrotes, mueblerías, librerías de libros antiguos, papelerías y quioscos de periódicos); b) personas vinculadas con el medio cultural local, que vivieron o trabajaron en la zona (creadores, intermediarios, emprendedores y comerciantes); $c$ ) creadores de tres grupos seleccionados relacionados con la actividad cultural de la zona: arquitectos, diseñadores y músicos. Además se aplicaron 26 entrevistas cortas (geonarrativas) a personas que transitan por circuitos o corredores seleccionados de la Roma-Condesa. Nos referimos a las calles que concentran las principales actividades tradicionales y culturales de la zona.

7 Del Directorio Estadístico Nacional de Unidades Económicas (DENUE, 2010, cuyos datos pueden solicitarse en: atencion. usuarios@inegi.org.mx, e InEgi, 2016); de los Censos de Población y Vivienda (Inegi, 2000 y 2010a); y de las Encuestas Nacionales de Ocupación y Empleo (INEGI, 2005, 2010b y 2015).

8 El análisis de las características sociodemográficas y laborales de los tres grupos de creativos seleccionados y su concentración geográfica se desarrolla en el libro producto de esta investigación, que está en proceso de edición. 
Mapa 1

Concentración de actividades culturales en la alcaldía Cuauhtémoc, Ciudad de México, 2016

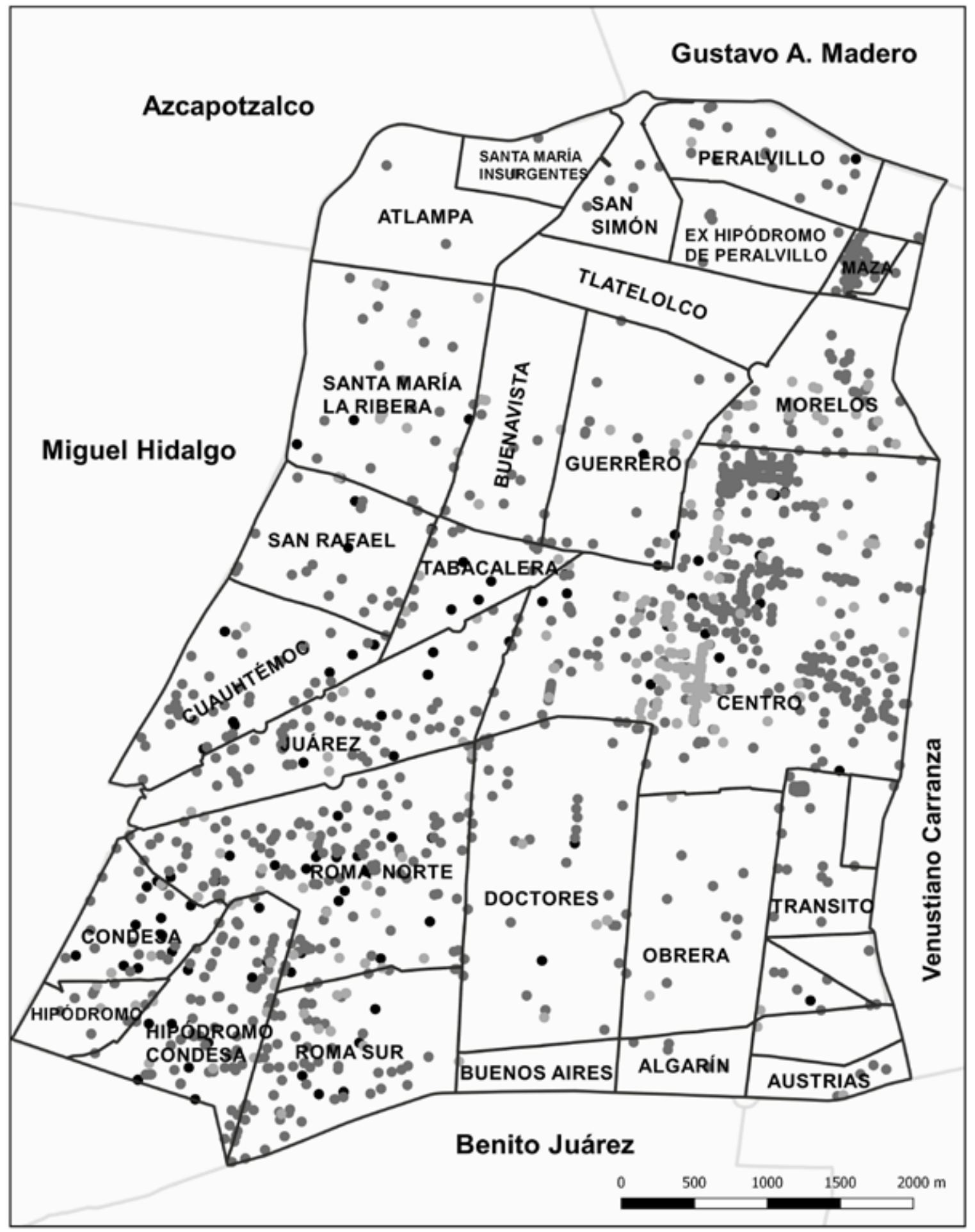

Sectores económicos

- Música

- Arquitectura y diseño

- Otras actividades artísticas
Elaboración propia con datos del

Directorio Estadístico Nacional

de Unidades Económicas (INEGI, 2016). 


\section{La zona de estudio}

A primera vista, la Roma-Condesa parece hoy en día un espacio moldeado por la intervención de ciertos estilos de consumo impuestos hegemónicamente, aunque, en realidad, como se busca demostrar en nuestra investigación, esta intervención surge "desde abajo" junto con los significados atribuidos por las personas a sus lugares de vida, trabajo y entretenimiento. A fin de cuentas, esta redefinición de los lugares ocupados por las personas en su vida cotidiana constituye, como señala García Canclini (2004: 41), una redefinición del lugar que ocupa la cultura en la vida social de los habitantes de este territorio urbano.

El surgimiento de la Roma-Condesa, como espacio cultural, se distingue de otros espacios culturales destacados de la ciudad: de manera señalada del Centro Histórico (que constituye el principal núcleo histórico de concentración de instituciones políticas y actividades patrimoniales y culturales del país), y de Coyoacán y San Ángel, cuya historia moderna está muy influenciada por la proximidad de grandes centros educativos, como Ciudad Universitaria y el Centro Nacional de las Artes. En contraste con estos otros espacios culturales, la Roma-Condesa tiene una conformación urbana más orgánica y espontánea, debido a la centralidad de sus barrios, el valor patrimonial de su estructura urbano-arquitectónica y su vocación histórica originaria que nace de ser residencia de artistas e intelectuales.

Este perfil espontáneo, resultado de fenómenos imprevistos como los sismos de 1985, trajo consigo

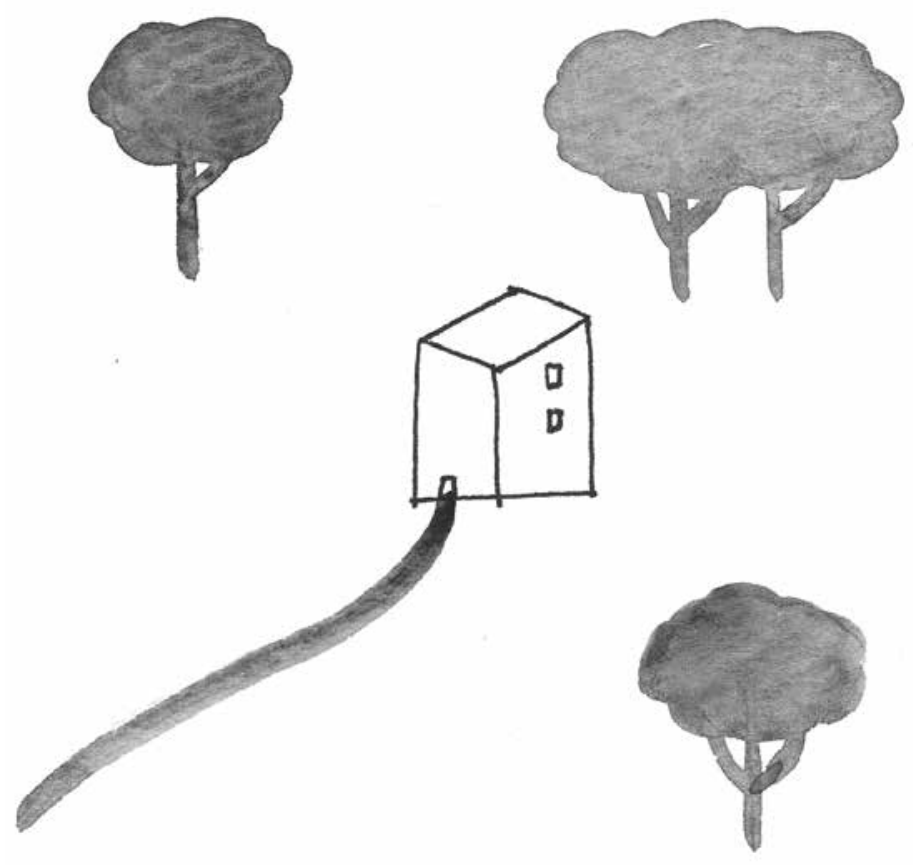

formas de pertenencia territorial diferenciadas. Para algunos habitantes de la Roma-Condesa, esta pertenencia pasa por la recreación de la memoria en el sentido otorgado por Pierre Nora, citado por Jodelet (2010: 81): una memoria atada a los sitios emblemáticos y a los lugares de la vida cotidiana. Para otros, la relación con el espacio habitado se construye desde el presente, como una elección que deviene en un sentimiento de pertenencia imaginaria a ciertos espacios "congruentes con sus vidas”. Al margen de lo que esto último signifique, debe tenerse en cuenta el carácter fluido de las percepciones de la gente sobre los lugares que habita (Massey, 1993, 1994). En algunos casos, esta pertenencia desborda lo local a través de las nuevas formas de comunicación, como sucede con los procesos culturales que se apoyan en las nuevas tecnologías y en las redes sociales, pero en general sus ataduras implican redes sociales locales que vinculan los lugares de residencia, trabajo y entretenimiento de las personas. De acuerdo con Savage, Bagnall y Longhurst (2005: 208), estos lugares de pertenencia son los sitios "donde la gente se mueve y coloca sus raíces", aunque sea provisionalmente, produciendo un sentimiento que se expresa, por un lado, en rutinas locales de trabajo, relaciones domésticas y entretenimiento, y, por otro, en la movilidad de sus imaginarios sociales.

Los imaginarios de la zona Roma-Condesa corresponden en parte a la narrativa sobre su identidad original de aspiración europea-que se remite a finales del siglo xix en el caso de la Roma, y a inicios del siglo xx para la Condesa-, que hace referencia en concreto a los espacios públicos (parques, camellones, glorietas, banquetas) concebidos para el encuentro y la convivencia de sus habitantes. Sobre estas imágenes han surgido otras que conciernen a los estilos de vida cosmopolitas de los nuevos residentes, que encuentran en esta zona los lugares para vivir, trabajar y consumir relacionados con la cultura y la creación artística.

En el caso de la Roma-Condesa, estos lugares tienen su asiento en editoriales, despachos de arquitectura y diseño, casas productoras de cine, estudios de grabación y talleres de artistas plásticos, además de los sitios de consumo cultural y comercial, como tiendas de diseño de objetos, muebles y moda, galerías, departamentos vanguardistas, y los de carácter lúdico y recreativo, como cines de arte, foros y festivales de música alternativa.

Este espacio cultural alternativo se caracteriza también por el uso intensivo del espacio público con un sentido artístico y político vinculado con diversas opciones de consumo y entretenimiento. Bares, restaurantes, mercadillos orgánicos, tiendas gourmet, peluquerías, gimnasios, centros nocturnos, ferias 
comerciales y festivales artísticos complementan este paisaje variopinto. En general, la concentración de estos lugares de producción cultural, consumo y recreación es lo que transforma a estos espacios de la Ciudad de México, que antes tuvieron una vida de barrio tradicional, en espacios culturales alternativos. ${ }^{9}$

\section{La Roma-Condesa, ¿de qué tipo de espacio cultural estamos hablando? Líneas de investigación}

Si nos atenemos al análisis cualitativo de este laboratorio urbano conviene destacar tres líneas de reflexión (que podrían leerse como hipótesis de trabajo) que muestran sus singularidades en tres aspectos principales: 1) el impacto de los sismos de 1985, 2) el carácter heterogéneo de la economía local y 3) la disputa por el espacio.

\section{Los sismos de 1985 y sus consecuencias}

El sismo del 19 de septiembre de 1985 y sus réplicas afectaron sobre todo a las colonias del centro de la ciudad, por estar construidas en lo que fue una zona lacustre. Las múltiples crónicas, ensayos y libros sobre este evento telúrico describen un panorama de destrucción y muerte, seguido por la desolación y el abandono de las áreas más dañadas, como el Centro Histórico y sus colonias colindantes, entre las cuales sobresalen la Juárez, la Roma y la Condesa. En el caso de estas dos últimas, y como consecuencia de la emigración de muchos de sus habitantes, el valor de los inmuebles decreció. A su vez, este declive del mercado inmobiliario atraería por sus rentas bajas a una población de menor poder adquisitivo y a especuladores que aprovecharon la crisis producida por los sismos para iniciar un proceso de renovación urbana.
Su repoblamiento paulatino se aceleró hacia mediados de la primera década del siglo xxI, como resultado de las políticas de redensificación impuestas por el llamado Bando Dos puesto en marcha en 2001. ${ }^{10}$ Estas medidas favorecieron la llegada de desarrolladores inmobiliarios alentados por la especulación urbana. A la postre, estos cambios provocaron el conocido círculo de regeneración urbana y el alza significativa de los precios de bienes raíces. ${ }^{11}$

Derivado de estos fenómenos, que alteraron drásticamente los usos del suelo de la zona, en la actualidad conviven casas unifamiliares, muchas convertidas en comercios, y nuevos edificios de departamentos, que han ganado terreno y se anuncian como urban lofts para atraer a la nueva clientela de jóvenes hipsters. ${ }^{12}$

Con todo, lo que hoy se tiene está lejos de parecerse a la imagen proyectada de los nuevos centros de negocios, comerciales y de consumo de las ciudades del primer mundo, adecuados a las necesidades de la llamada clase creativa. A diferencia de estos prototipos de la creatividad urbana postindustrial o neoindustrial (Pratt, 2008: 112 y 2009: 3), la Roma-Condesa sigue constituyendo un espacio que conserva la esencia de lo que fue desde su origen: una zona residencial, con arquitectura ecléctica y generosas áreas verdes, compuestas por parques, camellones, plazas y glorietas de influencia europea. ${ }^{13}$ Esta riqueza en su arquitectura y entorno urbano ha jugado un papel cardinal en la experiencia de vida de sus habitantes $\mathrm{y}$, sin duda, continúa siendo un factor de atracción para los artistas y creadores que llegaron en las últimas décadas.

A la par de esta importante renovación poblacional, la vida comercial adquirió una nueva intensidad, en particular en las colonias Hipódromo y Condesa. En la colonia Roma, este renacimiento del consumo cultural llevó más tiempo, y estuvo igualmente acompañado por el establecimiento de librerías, galerías de arte y centros culturales, museos, cafés, bares y restaurantes. Este boom de lugares destinados al entretenimiento

9 Estos espacios culturales se localizan en algunos fragmentos, barrios y colonias de la Ciudad de México, en los que el patrimonio cultural y los sitios de memoria han adquirido un nuevo valor físico, social y simbólico a la luz de la nueva centralidad de prácticas y lugares de creación y consumo (Duhau y Giglia, 2016).

10 Se conoce como Bando Dos al conjunto de políticas públicas urbanas que entraron en vigor en 2001, orientadas a la redensificación de cuatro delegaciones centrales -Miguel Hidalgo, Benito Juárez, Cuauhtémoc y Venustiano Carranza- y al control del crecimiento de la periferia.

${ }^{11}$ Entre 2010 y 2015 estas colonias experimentaron un repunte importante de los precios de los bienes raíces, incluso, duplicaron su valor. "Colonias 'trendy' del DF sufren burbuja de precios, alertan”, en El Financiero, 9 de diciembre de 2015 <http://www.elfinanciero.com.mx/empresas/colonias-trendy-del-df-sufren-burbuja-de-precios-alertan.html> [25 de diciembre de 2017].

${ }^{12}$ Se denominan hipsters a los jóvenes bohemios de clase media-alta que se establecen en barrios en proceso de gentrificación. Sus gustos incluyen tendencias alejadas de las corrientes mainstream. Gustan de música alternativa, moda que incluye lo vintage, alimentos orgánicos, productos artesanales y tienen posiciones políticas progresistas (Haddow, 2008).

${ }^{13}$ Destacan en la Roma las casonas porfirianas y algunos de los primeros edificios de departamentos, y, en la Condesa, las casas y los edificios art déco, californianos y funcionalistas. Es una de las áreas de la ciudad con mayor número de edificios con valor patrimonial (Perló, 1988; Tavares, 1995; Neri, 2009; Contreras, 2010). 
y a la producción y consumo cultural atrajo a otros negocios dedicados al diseño gráfico, museístico, de interiores y de moda, a la vez que reavivó algunos de los viejos lugares de la economía tradicional duramente afectados por el terremoto.

Se trata, pues, de un espacio ecléctico, donde conviven sitios de memoria de indudable valor patrimonial con las nuevas actividades creativas que han profundizado su carácter heterogéneo y multicultural.

\section{Complejidad y fluidez}

de la economía local

Un rasgo distintivo de este espacio es la heterogeneidad de su vida comercial y de servicios. De manera desigual, en este espacio se entreveran los típicos establecimientos de barrio -ferreterías, peluquerías, tortillerías y abarrotes- con aquellos de rango medio dedicados a la hotelería, la educación y la salud. Al lado de esta economía barrial, desde principios del siglo xxi despuntó una economía cultural y creativa, integrada por galerías de arte, tiendas de moda y diseño, acompañada por lugares de entretenimiento y recreación como restaurantes, cafeterías, bares y mercados gourmet. De algún modo, esta economía mixta recuerda a los lugares que Jacobs ( 1961 , cit. en Zukin, 2010: 226 y 234) llamó de "destino cultural", porque reinventan en sus entrañas la autenticidad de la tradición, pero en un contexto que proyecta "la visión de un nuevo comienzo" (en el que predominan los gustos cosmopolitas de la nueva clase de artistas y creadores que habita y trabaja en la zona).

Por su parte, la informalidad, lejos de separar el mundo tradicional del moderno, parece ser la sustancia que los junta y en la que florecen los más extraños productos y servicios new age, como la comida gourmet y las "terapias energéticas" para mascotas, las modas sofisticadas de las clases de meditación y de yoga al aire libre y la venta de hierbas de olor y jabones orgánicos en las calles, todo ello combinado con la oferta de artesanías. Al unísono, se observan diversas expresiones de la histórica economía urbana de la pobreza. Las más visibles y normalizadas cobran vida en los puestos callejeros de comida, ropa usada, baratijas, discos y películas pirata que se amontonan alrededor de las estaciones del metro cercanas a estas colonias. Otras maneras más soterradas de la informalidad urbana aparecen de forma esporádica en la lucha entre mafias por el control de espacios de estacionamiento en la vía pública, relacionadas además con la prostitución, la indigencia, el narcomenudeo, el cobro por el "derecho de piso" a comerciantes y los asaltos (últimamente a la alza) a transeúntes y comercios y restaurantes de moda. ${ }^{14}$

Cabe recordar que muchas de las actividades de la moderna economía creativa también tienen un carácter informal. Ejemplo de ello son los despachos de diseño o arquitectura que operan "ocultos" en casas habitación o los trabajos freelance que realizan muchos profesionistas vinculados con los procesos culturales y que no se declaran ante el fisco. En la Roma-Condesa, como en el resto de la ciudad, estas prácticas variadas de la economía formal e informal están imbricadas de manera tan íntima que es imposible diferenciarlas por ser mutuamente constitutivas.

\section{Conflicto e identidad territorial}

Esta reinvención de la Roma-Condesa ha sido un proceso largo, que por más de tres décadas ha confrontado las voluntades de diversos sectores e intereses sociales, comerciales, culturales y especulativos. Es por ello que, lejos de producirse una transformación urbana radical en las colonias que constituyen este corredor, lo que se ha observado en este tiempo son cambios desiguales que pugnan por su conservación como zona preferentemente habitacional y la defensa de sus vestigios patrimoniales y, en el otro extremo, por el fomento de proyectos habitacionales integrados a las actividades comerciales y festivas que responden a una lógica mercantil. En medio estarían quienes promueven una integración mejor ajustada entre los sujetos que defienden la identidad barrial apegada a sus orígenes y los que están por una economía cultural con fronteras simbólicas translocales.

Esta dinámica multicultural, pluriidentitaria $\mathrm{y}$ multiclasista, contuvo por buen tiempo una gentrificación más radical, como la que ha sucedido en otros sitios, por ejemplo en Santa $\mathrm{Fe}$, al poniente de la ciudad (Moreno Carranco, 2015; Pérez Negrete, 2010; Cornejo Portugal y Bellon Cárdenas, 2001; Kunz Bolaños, 2001), donde se produjo la expulsión de tajo de los antiguos propietarios y arrendatarios de casa habitación y comercios tradicionales. Aunque en la

\footnotetext{
${ }^{14}$ Según el reporte emitido por el Observatorio Nacional Ciudadano, a mediados de 2017 la delegación Cuauhtémoc, hoy alcaldía, reportó 714 casos de robo a negocio en 2016. Autoridades de esa demarcación aseguraron que en el mismo año sólo existieron 24 denuncias en el corredor Roma-Condesa; para mediados de 2017 ya se habían reportado 22 denuncias en esta zona (Moguel, 2017).
} 
Roma-Condesa muchos de sus antiguos pobladores han sido finalmente desplazados por los nuevos proyectos y la especulación urbana, la lucha por la defensa del patrimonio y por acuerdos razonables entre distintas posturas ha abierto, por momentos, pequeños pero significativos islotes de tolerancia en este espacio en disputa. A pesar de la importante alza en las rentas, tanto habitacionales como comerciales y de oficinas, se mantienen aquí muchos de los habitantes y comerciantes que residen y trabajan desde hace más de 30 años en la zona. Según Delgadillo (2016: 121), en la actualidad casi un cuarto de la población (23.4\%) de la Roma-Condesa lleva más de 20 años en ella, mientras otro tanto (24.7\%) siempre ha vivido allí, por ende, casi la mitad de los pobladores lleva más de 20 años en las colonias. También es relevante recordar que este espacio ha sido históricamente habitado por clases medias. Como consecuencia, la gentrificación muestra rasgos sutiles que, en muchos casos, hablan más de una nueva dinámica poblacional que del desplazamiento de habitantes.

Esto último se expresa de manera distinta en las cinco colonias que constituyen la Roma-Condesa. Lo que genéricamente llamamos la Condesa-que incluye las colonias Condesa, Hipódromo e Hipódromo Condesa-fue desde sus orígenes un espacio habitado por profesionistas, artistas e intelectuales de clase media y media alta. El hecho de que la Condesa fuera sólo ligeramente afectada por los sismos de 1985, en comparación con otras colonias mucho más dañadas, permitió que su reconstrucción fuera más rápida, circunstancia aprovechada tanto por las firmas de arquitectos que buscaron establecerse en el lugar, como por los especuladores urbanos. El arribo de una nueva población de artistas y creadores a la zona se produjo en este contexto más favorable, así como el desarrollo de proyectos culturales y comerciales que buscaban revivirla. Como resultado de estos diversos proyectos e intereses emergió, a partir de los años noventa, en el corazón de la Condesa, una mancha muy densa de cafés, bares y restaurantes, que terminó con la tranquilidad de algunas calles -por ejemplo $\mathrm{Mi}$ choacán, Nuevo León y Tamaulipas- en lo que era una zona habitacional privilegiada. La debilidad y corrupción de las autoridades locales para controlar este boom especulativo y comercial agudizó la disputa entre los habitantes y comerciantes tradicionales y los especuladores inmobiliarios, comerciantes y residentes de nuevo cuño (Neri, 2009).

Por su parte, la Roma, dividida en Roma Norte y Roma Sur, durante años fue una zona más heterogénea. Aunque la Roma Norte fue creada para satisfacer las necesidades de las élites urbanas de inicios del siglo $\mathrm{xx}$, por lo cual tiene lotes más grandes y construcciones más lujosas, con el tiempo muchas de sus grandes casonas se convirtieron en vecindades ocupadas por sectores populares y oficinas y comercios pequeños y medianos.

Los efectos destructivos de los sismos de 1985 agudizaron estas diferencias socioespaciales, lo que a la postre prolongó la recuperación de estas colonias y dificultó la armonización de los intereses en pugna. Esta complejidad social se expresó también en un avance más pausado y menos invasivo de los proyectos comerciales y habitacionales. A pesar de eso, actualmente la mayoría de los restaurantes, comercios y galerías más prestigiosos se ubica en la Roma Norte y ocupa muchos de los edificios de mayor valor arquitectónico.

A fin de cuentas, lo que observamos en ambos casos es una reconversión constante, contradictoria, por etapas, a veces irreversible, de este espacio urbano, como resultado de disputas e interacciones conflictivas entre agentes varios: comerciantes, desarrolladores inmobiliarios y residentes. En medio de este proceso, vemos cómo se manifiestan, por un lado, los anhelos de los antiguos habitantes por recobrar el paraíso perdido ante la saturación comercializadora y el "ruido" que eso provoca $y$, por otro lado, el bullicio de una clase media alimentada por las nuevas migraciones

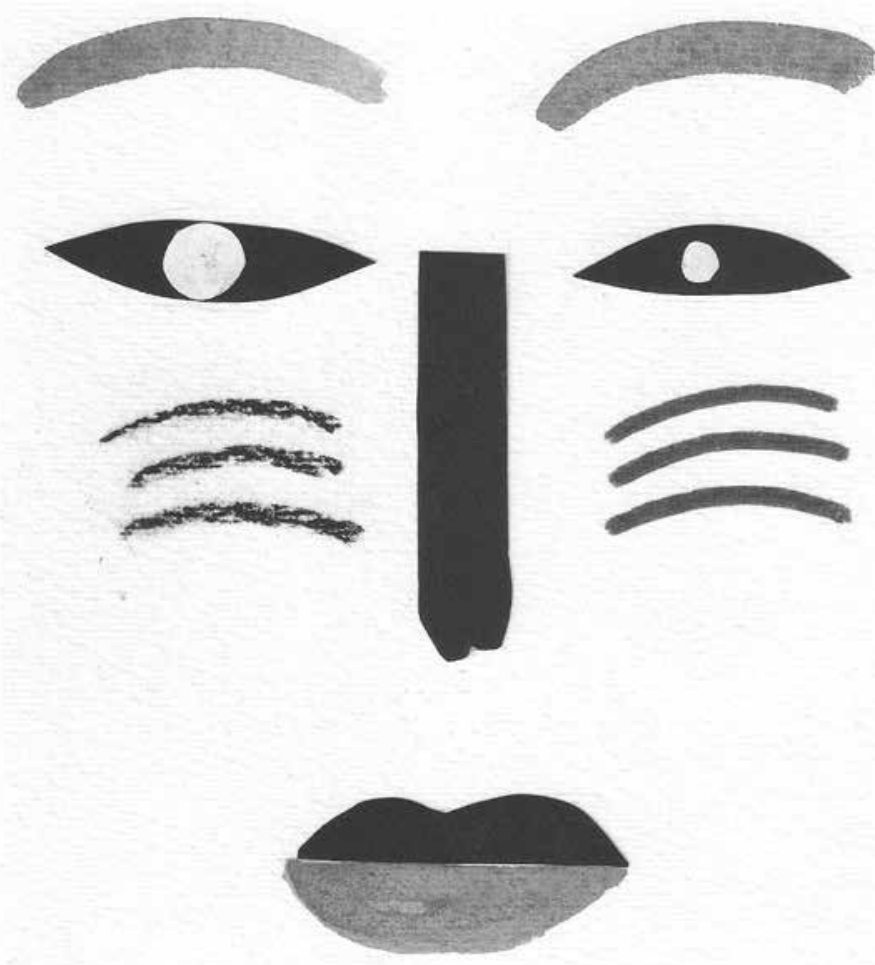


nacionales e internacionales, y la presencia de jóvenes y de personas de edad media proclives a un estilo de vida sostenido en el consumo hipster. No obstante, la convivencia, a veces complicada, de estos grupos sociales y de las distintas representaciones sociales del lugar está lejos de provocar una polarización excluyente, que sí puede advertirse en otros espacios de la Ciudad de México, como Santa Fe, "el mayor emprendimiento de urbanismo global en América Latina”, o Polanco, que alberga el "Rodeo Drive local" (Moreno Carranco, 2015). La Roma-Condesa, en medio de sus contradicciones, abre posibilidades para la existencia de un cierto habitus de la diferencia, que permite la presencia de áreas de tolerancia, como los parques y plazas o los diversos lugares de entretenimiento donde se habilita el rompimiento de normas y roles sexuales, culturales y sociales establecidos, la reconversión creativa de los mundos de trabajo y de vida que buscan acoplarse a las reglas de un mercado cultural hiperflexibilizado, junto con cambios propensos al consumo y la especulación comercial (Zukin, 2010: 136).

Según se explicó líneas arriba, este espacio "espontáneo", que forma parte de un orden urbano de dimensiones metropolitanas, se asemeja a los denominados "espacios disputados" que emergen como producto de las tensiones entre los resabios históricos de la ciudad moderna y los nuevos usos recreativos y comerciales de estos lugares (Duhau y Giglia, 2016: 48-49). Lo que interesa destacar en esta investigación son los efectos socioespaciales de estas tensiones entre actores que compiten por los usos que se debe dar al espacio bajo dominio privado, y los usos y formas de aprovechamiento de los espacios públicos en un entorno moldeado por la intervención de la cultura y la mercantilización de la creatividad. En suma, se trata de desmantelar las narrativas generalizantes sobre los procesos de gentrificación, la homogeneización y pérdida de identidad de los llamados SoHos urbanos, a través de una mirada que parte de la experiencia de los sujetos que habitan esta zona.

\section{Otro sismo: 19S 2017}

En el 32 aniversario del sismo de 1985, paradójicamente también un 19 de septiembre, otro movimiento telúrico de magnitud 7.1 en la escala de Richter sacudió a la Ciudad de México. Esta vez la Roma-Condesa concentró siete del total de 38 edificios colapsados en la ciudad. La colonia más dañada fue la Hipódromo con cuatro derrumbes. La tragedia revivió sentimientos y acciones que recordaron los temblores de 1985. La respuesta de los vecinos en esta zona fue especialmente solidaria: de forma inmediata la gente se organizó para mover escombros e intentar ayudar a las víctimas. A unas horas del evento, sitios como los parques México y España, la glorieta de Popocatépetl, el Huerto Roma Verde, casas y edificios en general se transformaron en centros de acopio. Grupos de WhatsApp y otras redes sociales organizaron la entrega de apoyo y ayudaron a dirigir a los voluntarios. A pesar de que en muchas zonas de la ciudad la normalidad continuó, prácticamente sin interrupciones, en los barrios afectados el tiempo pareció detenerse y tardó meses en regresar a la normalidad.

En los días siguientes al sismo aparecieron camiones de mudanzas en las calles. En la prensa se leían afirmaciones como: "El impacto inmediato se dará en el costo de las rentas en estos lugares. En cuestión de horas, de unos cuantos días, la emblemática Avenida Ámsterdam ha quedado deshabitada" (Molet, 2017); y, encabezados como: "El sismo amenaza el crecimiento y la popularidad de Roma-Condesa", en The New York Times Es (Semple y Linares, 2017); "El sismo terminará con la fiebre por vivir en la Roma y Condesa", en Forbes México (Solís y Zúniga, 2017); o "La Roma y la Condesa, dos de las colonias más afectadas tras el terremoto del 19 de septiembre, se enfrentan a un oscuro panorama en el mercado inmobiliario" (Molet, 2017). Un cambio radical en la percepción sobre la Roma-Condesa si consideramos que ésta había sido calificada como el "Mexico City's reigning axis of cool" ("el eje reinante de lo cool en la Ciudad de México") en GQ Magazine unos meses antes (Uyehara, 2017).

A más de dos años del temblor, podemos afirmar que no hubo cambios significativos en los precios de los inmuebles. De acuerdo con Alejandro Kuri Pheres, presidente nacional de la Asociación Mexicana de Profesionales Inmobiliarios, "el precio de la vivienda se mantuvo estable tras el sismo incluso en los puntos afectados de la ciudad como la zona de Roma-Condesa (Navarrete, 2018). Esto se explica en parte por el hecho de que la mayoría de los damnificados prefirieron permanecer en la zona debido a la alta calidad de vida de las colonias. A pesar de que no hubo una depreciación inmobiliaria, la vida diaria se alteró de forma importante. El número de visitantes descendió significativamente provocando el cierre de restaurantes, peluquerías, farmacias y muchos otros negocios de larga tradición, lo que ha propiciado nuevos giros. Aún a fines de 2019, al caminar por las calles, encontramos lotes vacíos, edificios acordonados y desocupados y otros en proceso de demolición, esto es especialmente visible sobre avenida Ámsterdam y alrededor del Parque México, que fue el área más dañada. De manera simultánea, la identidad barrial se ha 
fortalecido con acciones como actividades culturales, celebraciones conmemorativas en espacios públicos y campañas como \#AquíSigo, que tuvo la intención de reactivar la vida y economía de las colonias. Estas iniciativas han logrado que los barrios se recuperen con sus habitantes actuales en vez de ser abandonados como sucedió en 1985.

\section{Conclusiones}

En este artículo buscamos destacar los procesos de constitución de lo que se denominó espacio cultural alternativo en el contexto urbano de la Ciudad de México. Nuestro propósito fue hacer patente la especificidad de ciertos espacios reconocidos por la concentración de actividades culturales y de creación, y por los vínculos estrechos entre los lugares de habitación, trabajo y entretenimiento.

A través de este término, reconocemos la existencia de un tipo de "microórdenes" culturales especializados en sus funciones y relaciones, y regidos por un orden esencial, territorial, simbólico, cultural, político, económico e histórico; la "ciudad central", que marca el ritmo de la ciudad en su conjunto y del país. El espacio cultural estudiado forma parte de este núcleo hegemónico que tiene en el Centro Histórico su zona más densa. Por eso también resulta distinto de otros lugares de concentración de cultura y arte que están fuera del centro urbano, como Coyoacán y San Ángel. Ésta es la hipótesis principal de nuestra investigación.

Lo que tratamos de mostrar son las particularidades que hacen de la Roma-Condesa una zona cultural caracterizada por la convivencia entre espacios habitacionales, de trabajo y de consumo recreativo. Distinto del Centro Histórico, la Roma-Condesa continúa respondiendo a la imagen primigenia de las clases medias que la señalaban como un lugar privilegiado para vivir. A pesar de los cambios suscitados por los sismos de 1985 y 2017 , que afectaron desigualmente a esta zona, "habitar", en el sentido dado por Giglia (2012: 10), en relación con interpretar, reconocer y significar un lugar, sigue siendo lo que distingue este espacio-lugar en la elección de un cierto tipo de clases profesionistas. Este carácter de clase alude -a diferencia de los barrios obreros de la ciudad industrial que tenían como referencia la fábrica- a los nexos, reales o simbólicos, entre los lugares de residencia de estas clases medias que son asimismo sitios de trabajo y recreación. Esta aspiración se traduce en ciertas dinámicas urbanas, laborales y culturales, en los vínculos estrechos, pero también borrosos, entre los espacios públicos y privados, en las formas de movilidad de sus habitantes y visitantes, y en los estilos de vida y las disputas entre los residentes.

A partir de esta referencia empírica, definimos una postura teórica que toma distancia de las que se limitan a resaltar el sentido económico de este fenómeno de aglomeración cultural que deviene en creatividad y en diversas formas de renovación y gentrificación urbana.

De manera deliberada, nuestra propuesta atiende a la Roma-Condesa y sus singularidades. Este artículo se limita a caracterizar un ejemplo que ilustra las transformaciones urbanas de la ciudad en un periodo marcado por su transición a una "ciudad global", primordialmente sostenida en los servicios y el comercio. Dicha transición se vio acelerada por los sismos de 1985, y por otros de índole política y económica (como la firma del Tratado de Libre Comercio). En este marco, el surgimiento de ciertas "islas" culturales en la Ciudad de México muestra el nuevo y dinámico papel de la industria cultural en la economía y en los procesos de urbanización pero, sobre todo, aquel que la cultura puede jugar desde la mirada y las prácticas de los sujetos que dan sentido al espacio urbano. Esto se nota en el tipo de actividades, establecimientos, relaciones de trabajo, recreativas, y en el perfil sociodemográfico y laboral de los profesionistas de clase media que han llegado a vivir a estos sitios de cultura y recreación.

Se trata, pues, de dar cuenta del sentido progresivo del lugar, de las formas distintas y contrapuestas de habitarlo, de los imaginarios que se plasman en construcciones de clase que reflejan la nueva síntesis urbana creativa, de la renovada intervención de la cultura desde el territorio de sus actores, que es fuente de conflictos pero igualmente de la formación de un cierto habitus de la diferencia y de dinámicas multiculturales y multiclasistas. Habitus que, sin duda, apuntan a posibilidades de cambio menos abruptas y desgarradoras del tejido urbano que otras que hoy imperan en la Ciudad de México y en el país.

\section{Fuentes}

Alexander, J.

2000 Sociología cultural. Formas de clasificación en las sociedades complejas, Anthropos/Facultad Latinoamericana de Ciencias Sociales,

BAYARDO, R. Barcelona.

2013 "Políticas culturales y economía simbólica de las ciudades. Buenos Aires, en todo estás vos”, en Latin American Research Review, vol. 48, núm. especial, pp. 100-128.

Bell, Sarah L., Cassandra Phoenix,

Rebecca lovell y Benedict W. Wheeler

2015 "Using GPS and Geo-Narratives: A Methodological Approach for Understanding and 
Situating Everyday Green Space Encounters", en Area, vol. 47, núm. 1, pp. 88-96.

Contreras, A.

2010 "Los cambios urbanos del siglo xx y el trazo de la colonia Roma", en Investigación y diseño 06: Anuario del Posgrado de la División de Ciencias y Artes para el Diseño, Universidad Autónoma Metropolitana-Xochimilco, México, pp. 65-76.

Cornejo Portugal, I.

y E. Bellon Cárdenas

2001 "Prácticas culturales de apropiación simbólica en el Centro Comercial Santa Fe", en Convergencia, vol. 8, núm. 24, enero-abril, pp. 67-86.

Davis, M.

2004 "The Urbanization of Empire: Megacities and the Laws of Chaos", en Social Text, vol. 22, núm. 4, pp. 9-15.

Delgadillo, V.

2016 "Ciudad de México, quince años de desarrollo urbano intensivo: la gentrificación percibida", en Revista INVI, vol. 31, núm. 88, pp. 101129.

DraKe, G

2003 "This Place Gives me Space: Place and Creativity in the Creative Industries", en Geoforum, vol. 34, núm. 4, noviembre, pp. 511-524.

Duhau, E. y A. Giglia

2016 Metrópoli, espacio público y consumo, Fondo de Cultura Económica, México.

FLORIDA, R.

2002 The Rise of the Creative Class: And How it's Transforming Work, Leisure, Community and Everyday Life, Basic Books, Nueva York.

FLORIDA, R.

2003 "Cities and the Creative Class", en City \& Community, vol. 2, núm. 1, pp. 3-19.

FLORIDA, R.

2005 Cities and the Creative Class, Routledge, Nueva York.

FLORIDA, R.

2009 Las ciudades creativas. Por qué donde vives puede ser la decisión más importante, Paidós, Barcelona.

FriedmanN, J.

1995 "Where we Stand a Decade of World City

Research", en P. Knox y P. Taylor (coords.),

World Cities in a World System, Cambridge

University Press, Cambridge, pp. 21-47.

García CANClini, N.

2004 Diferentes, desiguales y desconectados. Mapas de la interculturalidad, Gedisa, Barcelona.

García Canclini, N.

y E. Piedras Feria

2008 Las industrias culturales y el desarrollo de México, Siglo xxi Editores/Facultad Latinoamericana de Ciencias Sociales, México.

Giglia, A.

2012 El habitar y la cultura. Perspectivas teóricas y de investigación, Anthropos / Universidad Autónoma Metropolitana-Iztapalapa, Barcelona y México.

HaDDOW, D.

2008 "Hipster: The Dead End of Western Civilization”, en Adbusters, 29 de julio.

HALL, P.

1997 "Megacities, World Cities and Global Cities", en The First Megacities Lecture, Rotterdam, febrero.

HaRt, G.

2002 Re-Placing Power in Post-Apartheid South Afri$c a$, University of California Press, Berkeley y Los Ángeles.

Herrera-Medina, E., H. Bonilla-Estévez

Y L. F. MolinA-PRIETO

2013 "Ciudades creativas: ¿paradigma económico para el diseño y la planeación urbana?", en Bitácora Urbano Territorial, vol. 22, núm. 1, enero-junio, pp. 11-20.

INEGI

2000 Muestra del XII Censo General de Población y Vivienda, Instituto Nacional de Estadística y Geografía <https://www.inegi.org.mx/ programas / ccpv/2000/default.html\#Micro datos $>$.

INEGI 2005

Encuesta Nacional de Ocupación y Empleo (ENOE). Segundo Trimestre, Instituto Nacional de Estadística y Geografía <https://www. inegi.org.mx/programas / enoe / 14ymas / ?ps= Microdatos>

INEGI

2010a Muestra del Censo de Población y Vivienda, Instituto Nacional de Estadística y Geografía <https: / /www.inegi.org.mx/programas / ccpv/2010/default.html\#Microdatos2010b>.

INEGI

2010b Encuesta Nacional de Ocupación y Empleo (ENOE). Segundo Trimestre, Instituto Nacional de Estadística y Geografía <https://www. inegi.org. $\mathrm{mx} /$ programas $/$ enoe $/ 14 \mathrm{ymas} /$ ?ps $=$ Microdatos>

INEGI

2015 Encuesta Nacional de Ocupación y Empleo (ENOE). Segundo Trimestre, Instituto Nacional de Estadística y Geografía <https://www. inegi.org.mx/programas / enoe/14ymas / ?ps= Microdatos $>$.

INEGI

2016 Directorio Estadístico Nacional de Unidades Económicas, Instituto Nacional de Estadística y Geografía <https: / / www.inegi.org.mx/app/ descarga/ $>$.

JODELET, D.

2010 "La memoria de los lugares urbanos", en Alteridades, año 20, núm. 39, pp. 81-89.

KRÄTKE, S.

2012 The Creative Capital of Cities: Interactive Knowledge Creation and The Urbanization Economies of Innovation, Wiley-Blackwell, Malden y Oxford

Kunz Bolaños, I.

2001 El mercado inmobiliario habitacional en la Ciudad de México, Plaza y Valdés, México.

LEFEBVRE, $\mathrm{H}$.

2013 La producción del espacio, Capitán Swing, Madrid.

Massey, D.

1993 "Power-geometry and a Progressive Sense of Place", en J. Bird, B. Curtis, T. Putnam, G. Robertson y L. Tickner (eds.), Mapping the Futures: Local Cultures, Global Change, Routledge, Londres, pp. 59-69.

Massey, D.

1994 Space, Place, and Gender, University of Minnesota Press, Mineápolis. 
Moguel, J.

2017 "Se desata la inseguridad en la Colonia Roma, en la Ciudad de México", en Uno TV, 26 de junio <https://www.cbsnews.com/news/sedesata-la-inseguridad-en-la-colonia-romaen-la-ciudad-de-mexico/> [28 de septiembre de 2018].

Molet, J.

2017 "Cómo afectará el sismo al valor de la Roma y la Condesa", en Alto Nivel, 28 de septiembre <www.altonivel.com.mx/afectara-sismoal-valor-la-roma-la-condesa/> [ 14 de abril de 2018].

Montgomery, J.

2003 "Cultural Quarters as Mechanisms for Urban Regeneration. Part 1: Conceptualising Cultural Quarters", en Planning, Practice \& Research, vol. 18, núm. 4, noviembre, pp. 293306.

Moreno Carranco, María

2015 Geografías en construcción: el megaproyecto de Santa Fe en la Ciudad de México, Universidad Autónoma Metropolitana, México.

NAVARRETE, S.

2018 "Pega inflación a precio de vivienda", en $R e$ forma, 30 de enero.

NERI, L.

2009 "El espacio público urbano como generador de la integración social en los vecindarios Roma y Condesa de la Ciudad de México 1985-2008”, tesis de maestría en Ciencias Sociales, Facultad Latinoamericana de Ciencias Sociales,

Newman, I. México.

Y C. R. BENZ

1998 Qualitative-Quantitative Research Methodology. Exploring the Interactive Continuum, Southern Illinois University Press, Carbondale.

Pérez Negrete, M.

2010 Ciudad, espacio y globalización: Santa Fe, Universidad Iberoamericana, Puebla.

Perló, M.

1988 "Historias de la Roma. Microhistoria de la ciudad de México", en Ensayos, núm. 19, octubre-marzo, pp. 159-170.

Pratt, A. C.

2008 "Creative Cities: The Cultural Industries and the Creative Class", en Geografiska Annaler: Series B. Human Geography, vol. 90, núm. 2,

Pratt, A. C. septiembre, pp. 107-117.

2009 "Urban Regeneration: From the Arts 'Feel Good' Factor to the Cultural Economy. Case Study of Hoxton, London", en Urban Studies, vol. 46, núm. 5-6, pp. 1041-1061.

RANADE, SHILPA

2007 "The Way She Moves: Mapping the Everyday Production of Gender-Space", en Economic and Political Weekly, vol. 42, núm. 17, abrilmayo, pp. 1519-1526.

SAssen, S.

1991 The Global City, Princeton University Press, Princeton.
SASSEN, S.

1994 Cities in a World Economy, Pine Forge Press, Thousand Oaks.

Savage, M., G. Bagnall

Y B. LONGHURST 2005 Globalization and Belonging, Sage, Londres.

Semple, K.

Y A. LINARES

2017 "El sismo amenaza el crecimiento y la popularidad de Roma- Condesa", en The New York Times Es, 22 de septiembre <https://www. nytimes.com/es/2017/09/22/roma-condesasismo-mexico-terremoto/> [22 de septiembre de 2018].

SOJA, E.

1996 Thirdspace: Journeys to Los Angeles and the Other Real-and-imagined places, Blackwell, Cambridge, Mass.

Solís, A.

Y E. ZÚNIIGA

2017 "El sismo terminará con la fiebre por vivir en la Roma y Condesa”, en Forbes México, 27 de septiembre <https: / /www.forbes.com.mx/elsismo-terminara-con-la-fiebre-por-vivir-enla-roma-y-condesa/> [27 de septiembre de 2018].

TAVAREs, E.

1995 Colonia Roma, Clío, México.

TAYLOR, P.

1997 "Hierarchical Tendencies amongst World Cities: A Global Research Proposal", en Cities, vol. 14, diciembre, pp. 323-332.

TAYLOR, P. 2004 World City Network: A Global Urban Analysis, Routledge, Londres.

Tremblay, D.-G., J.-L. Klein

Y J.-M. FONTAN

2009 Initiatives locales et développement socioterritorial, Télé-université, Université du Québec à Montréal, Quebec.

United Nations Conference

on Trade and Development

2010 Creative Economy Report 2010, United Nations, Washington, D. C.

UYEHARA, M. 2017

"Where to Stay, Eat, and Shop in Mexico City's Coolest Neighborhood", en GQ Magazine, 26 de julio <https: / / www.gq.com/story / neighborhood-guide-condesa-mexico-city> [26 de julio de 2018].

VIVANT, E.

Y D.-G. TREMBLAY

2010 "L'économie creative. Nota de recherché de la Chaire de recherché du Canada", en Enjeux socio-organisationnels de l'économie du savoir, núm. 10-02, noviembre.

ZuKin, SH. 2008 "Consuming Authenticity", en Cultural Stud-

ZuKIN, SH. ies, vol. 22, núm. 5, septiembre, pp. 724-748. 2010

Naked City: The Dead and Life of Authentic Urban Places, Oxford University Press, Nueva York. 